\title{
Design and Evaluation of a Novel Bio-Mimicking In Vitro Dissolution Test Apparatus for Floating Drug Delivery Systems
}

\author{
L. Baldaniya ${ }^{1, *}$, S. Saisivam², and M. Gohel ${ }^{1}$ \\ ${ }^{1}$ Department of Pharmaceutical Technology, Anand Pharmacy College, Anand, 388001, Gujarat, India \\ ${ }^{2}$ Department of Pharmaceutical Technology, N. R. Vekaria Institute of Pharmacy, Bilkha road, Junagadh, 362001, Gujarat, India
}

\begin{abstract}
The aim of the present study was to design a new biorelevant dissolution test apparatus for evaluating floating drug delivery systems. The gastric fluid secretion rate, volume of gastric fluid present in the stomach, and gastric emptying from the pylorus opening were taken into consideration. The material of construction was borosilicate glass. In vitro dissolution testing of pharmaceutical dosage forms is performed for quality control purposes and to establish in vitro-in vivo correlations (IVIVC). Compendial in vitro dissolution test apparatus are poor predictors of the in vivo performance of a floating drug delivery system (FDDS). The drawbacks associated with compendial and noncompendial dissolution test apparatus were rectified in the present study. A magnetic stir bar provided agitation of the dissolution medium for uniform mixing. The phenomenon of gastric emptying was mimicked by a special assembly attached at the bottom of the glass apparatus. The drug release study was conducted with USP Apparatus 2 (paddle) and an apparatus designed for a commercial floating product. The experiments were run at $37 \pm 0.5^{\circ} \mathrm{C}$ and a stirring speed of $75 \mathrm{rpm}$. Analysis of the data was performed by comparing drug release profiles using the similarity factor $f_{2}$ as a tool for the assessment of dissolution. In vivo performance was predicted using a convolution technique.
\end{abstract}

KEYWORDS: Dissolution apparatus; floating drug delivery system; biorelevant method; convolution technique; Cifran OD.

\section{INTRODUCTION}

$\mathrm{D}$ rug dissolution testing is an integral part of pharmaceutical formulation development (1) and is mainly used for deciding quality attributes of finished dosage forms. Drug dissolution testing is a regulatory requirement to build quality into the drug formulation (2). The test utilizes specialized equipment, commonly known as basket and paddle apparatus. These dissolution apparatus have official recognition throughout the world, mostly through pharmacopoeias (2). These apparatus are also described as dissolution Apparatus 1 and 2, respectively. In vitro dissolution testing of pharmaceutical dosage forms is carried out for quality control (3) and to establish in vivo-in vitro correlation (IVIVC). For the dissolution testing of floating drug delivery systems (FDDS), many scientists have proposed changes in the dissolution methodology. In the present study, an apparatus was designed to overcome the various drawbacks associated with presently compendial dissolution test apparatus, such as sticking of floating dosage forms on the rotating shaft. In this situation, the dosage form constantly rotates along with the shaft during the entire dissolution study period. Another shortcoming is sticking of a floating microparticulate system to the

*Corresponding author. sampling devices (pipette). The other points are the lack of an appropriate sampling method and the requirement of a large volume ( $\geq 900 \mathrm{~mL}$ ) of simulated gastric dissolution fluid, which can be cost intensive and requires a large sample size (4). Small size samples withdrawn from a large volume of fluid vessel may not be representative of the bulk liquid due to inadequate mixing (5). In some cases, vortex formation occurs in the dissolution medium resulting in entrapment of air bubbles, which may hinder drug release from the formulation. Also, compendial in vitro compendial dissolution apparatus do not mimic point-to-point conditions present in the stomach (3). All aforementioned limitations have an adverse impact on the dissolution profile of a drug. Hence, there is a need for a dedicated, designed apparatus for evaluating floating drug delivery systems. The present research work was undertaken to address these problems.

\section{MATERIAL AND METHODS}

Hydrochloric acid $(\mathrm{HCl})$ was procured from S. D. Fine Chemicals Ltd. India. Cifran OD (once daily) tablets were procured from a pharmacy. Carbamazepine was received from SUN Pharmaceuticals Ltd., Baroda, India. Methylcellulose and ethylcellulose were purchased from Yarrow Chem Product, India. The dissolution vessel was 

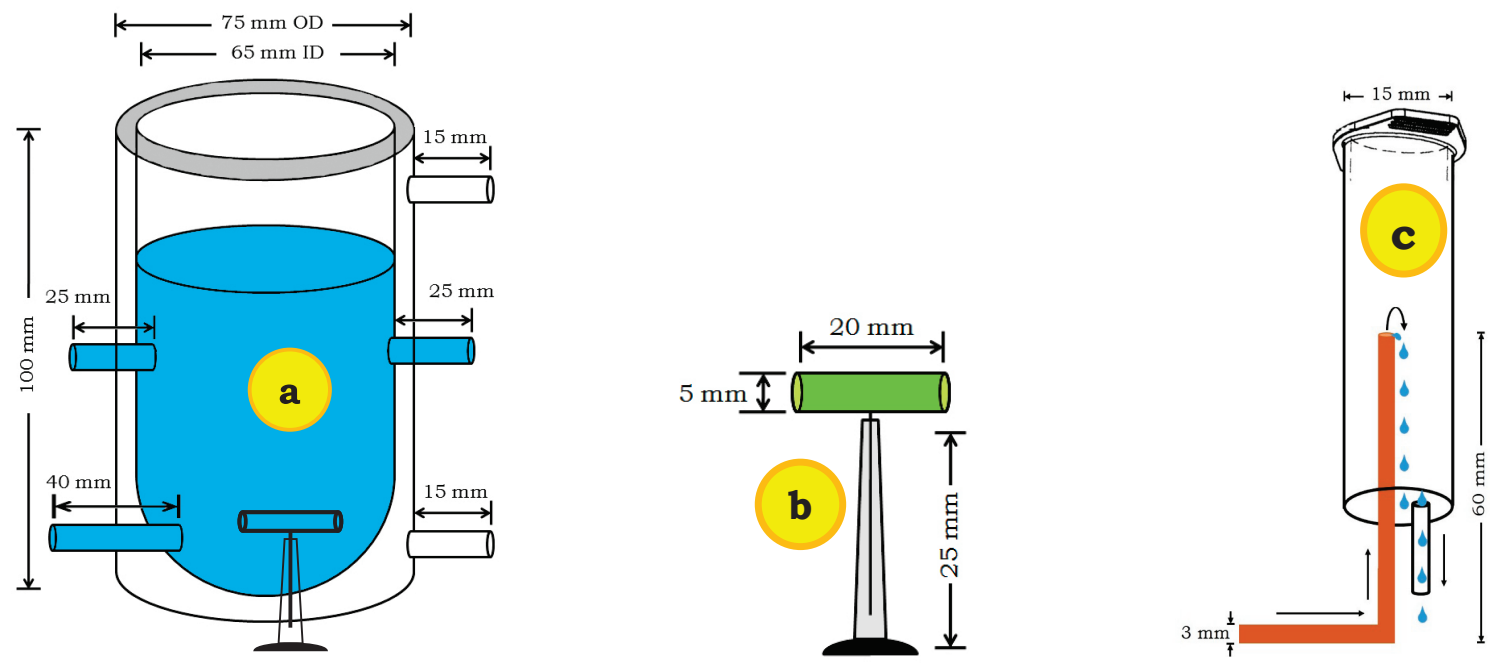

Figure 1. (a) Glass assembly, (b) magnetic stirring bar, and (c) side assembly, which acts as outlet (pyloric sphincter) for dissolution medium.

fabricated by a glass blower (Sun Instruments Pvt. Ltd., Ahmedabad) as per the design specification given by the authors. All the chemicals were of analytical grade and used as received.

An in vitro dissolution test apparatus (Figure 1a) was designed and fabricated to mimic the in vivo gastric acid release rate $(2 \mathrm{~mL} / \mathrm{min})$, volume of dissolution medium $(75 \mathrm{~mL})$, and emptying of the stomach (6). Agitation of the medium was done with a magnetic stirring bar rotating at $25 \mathrm{~mm}$ from the hemispherical bottom of the glass apparatus (Figure 1b). Depending upon the drug characteristics, an appropriate volume of sample was withdrawn for analysis.

In the test apparatus, the phenomenon of stomach emptying was simulated by a special assembly (Figure 1c) connected to the bottom of the apparatus. The test apparatus was also designed to simulate sink conditions with respect to accessibility of fresh dissolution medium surrounding the floating preparation (3). The performance of the proposed design was further validated and compared by a drug release study of formulated sustained-release floating microspheres of carbamazepine and a marketed formulation (Cifran OD tablets containing ciprofloxacin $500 \mathrm{mg}$ ) with USP Apparatus 2 (paddle). Experiments were run at $37 \pm 0.5^{\circ} \mathrm{C}$ with the rotating magnetic stirring bar at an agitation speed of $75 \mathrm{rpm}$ (7).

\section{Schematic Design of Dissolution Apparatus}

The assembly consists of a transparent cylindrical glass vessel with a hemispherical bottom (Figure 1a) and a $100-\mathrm{mL}$ capacity to contain $75 \mathrm{~mL}$ of gastric fluid. The temperature of the dissolution medium was maintained by a jacketed water bath (Figure 2). Water at $37 \pm 0.5^{\circ} \mathrm{C}$ was circulated through the jacket with the help of a small submersible pump. The assembly did not show any significant vibration. The magnetic stirring bar was positioned in such a way that the axis did not deviate from the vertical axis of the vessel and rotated smoothly (8). A tachometer, which measures rotational rate, was used to control the agitation speed of a magnetic stirring bar at $75 \mathrm{rpm}$. The distance between the inside hemispherical bottom of the vessel and the magnetic stirring bar was maintained at $25 \pm 2 \mathrm{~mm}$. It was difficult to rotate a magnetic stirring bar in a hemispherical bottom if kept as such without height. Moreover, a uniform motion of dissolution medium at the surface was not achieved. Hence, to achieve homogeneous turbulent agitation throughout the vessel, the stir bar was rotated at a specific

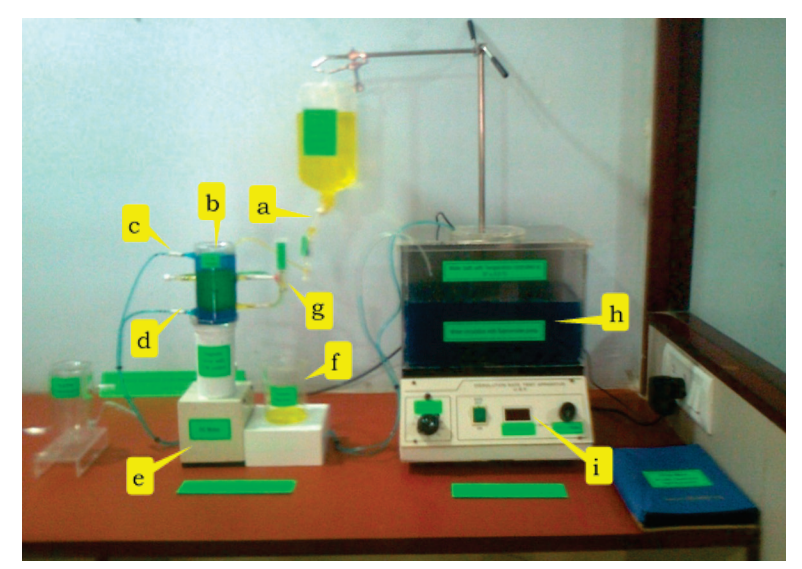

Figure 2. Fabricated glass assembly: (a) entry of dissolution medium from reservoir, (b) biomimicking glass assembly, (c) outlet for warm water, (d) inlet for warm water, (e) DC motor with tachometer, (f) sample collecting beaker, (g) sample flows from side arm attached at bottom, (h) warm water bath kept at $37 \pm 0.5^{\circ} \mathrm{C}$, (i) rpm display. 
height. Moreover, to ensure consistent results from test to test, various mechanical calibration parameters were considered as per FDA recommended specification (Table 1). An infusion bottle (reservoir for dissolution medium) containing gastric fluid $(0.1 \mathrm{~N} \mathrm{HCl})$ was mounted above the assembly to supply the dissolution medium at a flow rate of $2 \mathrm{~mL} / \mathrm{min}$, mimicking gastric fluid release (3). The flow rate was controlled by a regulator. Additionally, dissolution medium was diverted from the reservoir into two directions (left and right side) and perfused into the glass assembly. The dissolution medium containing dissolved drug flowed from the special assembly attached at the bottom of the apparatus at $2 \mathrm{~mL} / \mathrm{min}$. Samples of five milliliters were collected from a beaker, which was kept underneath the assembly. Special care was taken in the design of the side assembly to maintain a volume of $75 \mathrm{~mL}$ (Figure 1c).

Table 1. Mechanical Calibration Parameters Controlled for Instrument Qualification

\begin{tabular}{|c|c|c|c|}
\hline Parameter & Device & Observed & Tolerance \\
\hline Rotation speed & Tachometer sensor & $73-77 \mathrm{rpm}$ & $\pm 4 \%$ \\
\hline $\begin{array}{c}\text { Temperature of } \\
\text { medium }\end{array}$ & Temperature probe & $37 \pm 0.5^{\circ} \mathrm{C}$ & $\pm 0.5^{\circ} \mathrm{C}$ \\
\hline Vessel level & Bubble level sensor & $\begin{array}{c}\text { In the } \\
\text { center }\end{array}$ & $\pm 0.5^{\circ}$ \\
\hline $\begin{array}{c}\text { Vibration of } \\
\text { stirrer }\end{array}$ & Displacement & $\begin{array}{c}\text { Absence of } \\
\text { vibration }\end{array}$ & $\begin{array}{c}\leq 0.00254 \\
\mathrm{~mm}\end{array}$ \\
\hline $\begin{array}{c}\text { Rotating shaft } \\
\text { centering }\end{array}$ & Centering ring & $\pm 2 \mathrm{~mm}$ & $\pm 2 \mathrm{~mm}$ \\
\hline $\begin{array}{c}\text { Height of rotating } \\
\text { magnetic bar } \\
\text { from bottom of } \\
\text { the vessel }\end{array}$ & $\begin{array}{c}\text { Precise height fixed } \\
\text { for the rotating } \\
\text { assembly before } \\
\text { placing into the vessel }\end{array}$ & $25 \mathrm{~mm}$ & $\pm 2 \mathrm{~mm}$ \\
\hline $\begin{array}{c}\text { Dissolution } \\
\text { medium } \\
\text { evaporation }\end{array}$ & $\begin{array}{c}\text { Vessel covered with } \\
\text { lead }\end{array}$ & $0 \%$ & $\mathrm{None}$ \\
\hline $\begin{array}{c}\text { Media flow rate } \\
\text { from reservoir }\end{array}$ & Digital flow meter & $2 \mathrm{~mL} / \mathrm{min}$ & $\pm 0.1 \mathrm{~mL}$ \\
\hline
\end{tabular}

${ }^{a} D C$ motor was used in the magnetic stirrer. Hence, no vibration was seen in the assembly. Also, medium heating assembly is separate from main vessel. Vibration-proof mounting is recommended to minimize minor variability between batches.

\section{Preparation of Floating Microspheres of Carbamazepine}

Drug-loaded microspheres were prepared by an oil/water emulsion-solvent evaporation method. Carbamazepineloaded microspheres were prepared using ethyl cellulose, dichloromethane, acetone, sodium lauryl sulfate (SLS), and distilled water. The operative parameters were: (1) aqueous phase volume of $200 \mathrm{~mL}$, (2) organic phase volume of $150 \mathrm{~mL}$, (3) acetone/dichloromethane ratio of 2:1, (4) polymer/drug ratio of 2:1, (5) stirring rate of 1200 $\mathrm{rpm}$, and (6) SLS concentration of $0.15 \% \mathrm{w} / \mathrm{v}$.

\section{Influence of Experimental Variables}

\section{on Particle Size Distribution}

The drug-to-polymer ratio appears to influence the particle size distribution of microspheres. The polymer concentration is critical for the formation of microspheres, so the polymer concentration was varied to get a different drug-to-polymer ratio, keeping the drug concentration constant. When the drug-to-polymer ratio was increased from 1:0.25 to $1: 1$, the proportion of larger particles formed increased because the viscosity of the primary emulsion increased. Because of this increased viscosity, large emulsion droplets formed that precipitated as such, leading to an increase in the mean particle size.

Changing the stirring speed of the second emulsification process also influenced the mean particle size of the microspheres. When the stirring speed was decreased from 1200 to $600 \mathrm{rpm}$, the mean particle size of the microspheres increased. When the speed was increased from 900 to $1300 \mathrm{rpm}$, the size of the drug-loaded microspheres was uniform in the range of $298 \pm 18 \mu \mathrm{m}$.

The carbamazepine loaded microspheres of the optimized batch showed a $24.58 \pm 2.00^{\circ}$ angle of repose, $0.22 \pm 0.08$ $\mathrm{g} / \mathrm{mL}$ bulk density, $0.03 \pm 0.17 \mathrm{~g} / \mathrm{mL}$ tapped density, 11.70 $\pm 1.95 \%$ Carr's index, and $1.13 \pm 0.82$ Hausner ratio.

\section{Surface Morphology and Particle Size}

The average particle size of the microspheres was $291 \mu \mathrm{m}$. Samples for the scanning electron microscopy (SEM) analysis were prepared by sprinkling the microspheres on one side of a double-adhesive stub (9). The stub was then coated with gold. The microspheres were then observed with a scanning electron microscope model ESEM TMP + EDAX (Philips, Netherlands) at $30 \mathrm{kV}$. The samples included blank microspheres, drug-loaded microspheres, and the microspheres collected after the dissolution study. As shown in Figure 3, the microspheres were spherical, uniform in size, and porous. A surface study of the microspheres after dissolution showed bigger pores, suggesting that the drug was released through these channels.

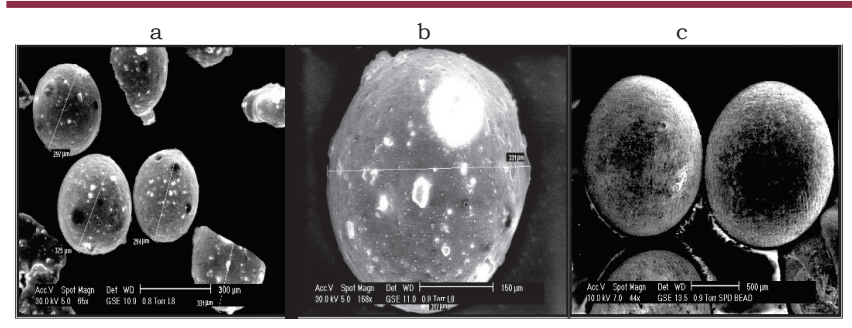

Figure 3. SEMs of (a) drug-loaded microspheres, (b) blank microspheres, and (c) microspheres collected after dissolution study. 


\section{In Vitro Buoyancy Study}

The in vitro floating test was performed in dissolution Apparatus 2 by spreading the floating microspheres on gastric fluid $(0.1 \mathrm{~N} \mathrm{HCl}, \mathrm{pH} 1.2)$ containing the surfactant (10). The medium was stirred at $75 \mathrm{rpm}$ at $37{ }^{\circ} \mathrm{C}$. After a specific time interval, both the floating and settled microspheres were collected and the buoyancy of the floating microspheres was calculated using the equation (10):

$$
\% \text { Bouyancy }=\frac{Q_{\mathrm{f}} \times 100}{Q_{\mathrm{f}}+Q_{\mathrm{s}}}
$$

where $Q_{\mathrm{f}}$ and $Q_{\mathrm{s}}$ are the masses of the floating and settled microspheres, respectively. Throughout the buoyancy study, it was observed that the microspheres floated for more than $16 \mathrm{hr}$ of testing.

\section{Performance Evaluation of Apparatus by Comparison of In Vitro Dissolution Profiles}

Sustained-Release Floating Microspheres of Carbamazepine

The microspheres equivalent to $100 \mathrm{mg}$ carbamazepine were filled into size 0 transparent hard-gelatin capsules (9). The dissolution study was performed in USP Apparatus 2 (paddle) as well as in the designed apparatus. In the case of the paddle method, the dissolution test was performed in $900 \mathrm{~mL}$ of $0.1 \mathrm{~N} \mathrm{HCl}$ maintained at $37 \pm 0.5{ }^{\circ} \mathrm{C}$ and stirred at $75 \mathrm{rpm}$. A $10-\mathrm{mL}$ sample was withdrawn from the dissolution apparatus at designated sampling times and replaced with an equal volume of fresh dissolution medium. In the designed apparatus, 5- $\mathrm{mL}$ sample was withdrawn from receiver beaker (Figure 2). There was no need of replacement with fresh medium in the proposed method, because fresh medium was supplied from the reservoir to maintain a constant volume. The samples were filtered through a $0.45-\mu \mathrm{m}$ membrane filter and diluted to a suitable concentration. The absorbance of these solutions was measured at $287 \mathrm{~nm}$ using a UV-vis spectrophotometer (Shimadzu 1800). The percentage drug release was plotted against time to construct a drug release profile for the formulation (Figure 4).

\section{Marketed Floating Tablet Formulation}

\section{Containing Ciprofloxacin $500 \mathrm{mg}$}

The release rate of ciprofloxacin from floating tablets (Cifran OD) was assessed with USP Apparatus 2 as well as with the designed apparatus (Figure 2). In the case of the Apparatus 2 method, the dissolution test was performed in $900 \mathrm{~mL}$ of $0.1 \mathrm{~N} \mathrm{HCl}$ maintained at $37 \pm 0.5^{\circ} \mathrm{C}$ and stirred at $75 \mathrm{rpm}$. A 10-mL sample was withdrawn from the dissolution apparatus at designated times and replaced with an equal volume of fresh dissolution medium. In

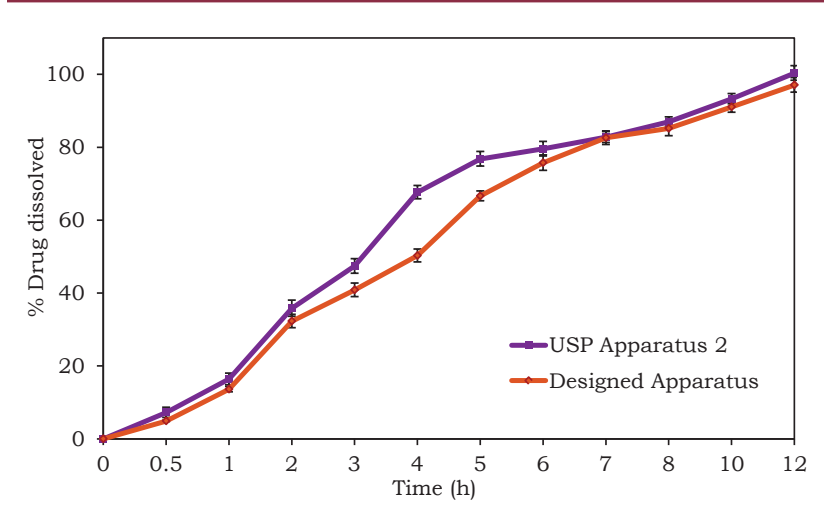

Figure 4. In vitro dissolution profile of floating microspheres of carbamazepine obtained from USP Apparatus 2 and designed apparatus.

the designed apparatus, 5-mL samples were withdrawn from the receiver beaker (Figure 2). There was no need of replacement with fresh medium in the proposed method, because fresh medium was supplied from the reservoir to maintain sink conditions. The samples were filtered through a $0.45-\mu \mathrm{m}$ membrane filter and diluted to a suitable concentration. The absorbance of these solutions was measured at $276 \mathrm{~nm}$ using a UV-vis spectrophotometer (Shimadzu 1800) (11). The percentage drug release was plotted against time to construct drug release profile for the formulation (Figure 5).

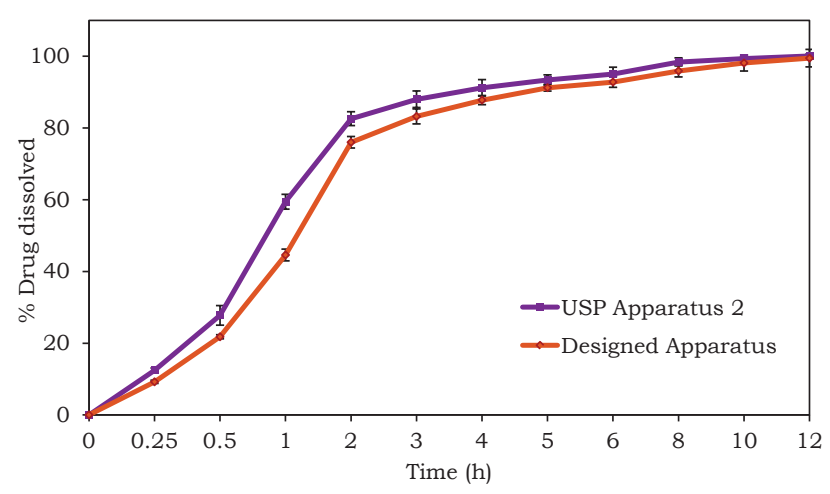

Figure 5. In vitro dissolution profile of ciprofloxacin (Cifran OD) obtained from USP Apparatus 2 and designed apparatus.

Model-Independent Approach (Similarity and Dissimilarity Indices)

A statistical comparison of the dissolution behavior of the floating drug delivery system (12) was done using a model-independent statistical approach. Using the fit factor $\left(f_{2}\right)$, the percentage drug released from both the floating microspheres of carbamazepine (Table 2) and the floating tablets of Cifran OD (Table 3 ) obtained from the USP method was compared with the results obtained from designed apparatus. This fit factor directly compares the 
difference between percent drug dissolved per unit time for a test (dissolution data from proposed design) and a reference (dissolution data from USP method) (13). The similarity factor, $f_{2}$, is defined by the following equation:

$$
f_{2}=50 \cdot \log \left\{\left[1+\frac{1}{n} \sum_{t=1}^{n}\left(R_{t}-T_{t}\right)^{2}\right]^{-0.5} \times 100\right\}
$$

where $n$ is the number of dissolution sampling times and $R_{t}$ and $T_{t}$ are the mean percentages dissolved at each time point for the reference and test dissolution profiles, respectively (14). For dissolution profiles to be considered similar, the $f_{2}$ value should be close to 100 . In general, $f_{2}$ values greater than 50 show similarity of the dissolution profiles $(12,15)$.

Table 2. In Vitro-In Vitro Dissolution Profile of Floating Microspheres of Carbamazepine ${ }^{a}$

\begin{tabular}{|c|c|c|}
\hline \multirow{2}{*}{ Time (min) } & USP Apparatus 2 & Designed Apparatus \\
\cline { 2 - 3 } & \%CDR \pm SD & \%CDR \pm SD \\
\hline 0 & $0.00 \pm 0.00$ & $0.00 \pm 0.00$ \\
\hline 15 & $7.23 \pm 1.40$ & $4.90 \pm 0.20$ \\
\hline 30 & $16.39 \pm 1.60$ & $13.61 \pm 0.75$ \\
\hline 60 & $35.80 \pm 1.21$ & $32.28 \pm 1.83$ \\
\hline 120 & $47.39 \pm 1.21$ & $40.84 \pm 1.86$ \\
\hline 180 & $67.64 \pm 1.83$ & $50.26 \pm 1.77$ \\
\hline 240 & $76.80 \pm 1.85$ & $66.62 \pm 1.35$ \\
\hline 300 & $79.55 \pm 1.32$ & $75.73 \pm 1.11$ \\
\hline 360 & $82.75 \pm 1.47$ & $82.57 \pm 1.87$ \\
\hline 480 & $86.98 \pm 1.20$ & $85.17 \pm 1.05$ \\
\hline
\end{tabular}

${ }^{a} n=3 ; \% C D R$ : percentage cumulative drug release; SD: standard deviation.

Table 3. In Vitro-In Vitro Dissolution Profile of Cifran OD Tablet ${ }^{a}$

\begin{tabular}{|c|c|c|}
\hline \multirow{2}{*}{ Time $(\min )$} & USP type 2 & Designed apparatus \\
\cline { 2 - 3 } & \%CDR \pm SD & \%CDR \pm SD \\
\hline 0 & $0.00 \pm 0.00$ & $0.00 \pm 0.00$ \\
\hline 15 & $12.45 \pm 0.61$ & $9.21 \pm 0.45$ \\
\hline 30 & $27.73 \pm 1.73$ & $21.77 \pm 0.57$ \\
\hline 60 & $59.41 \pm 1.06$ & $44.57 \pm 1.64$ \\
\hline 120 & $82.57 \pm 1.93$ & $75.99 \pm 1.60$ \\
\hline 180 & $87.99 \pm 1.30$ & $83.20 \pm 1.09$ \\
\hline 240 & $91.17 \pm 1.29$ & $87.75 \pm 1.28$ \\
\hline${ }^{a} n=3$ & \multicolumn{2}{|c}{} \\
\hline
\end{tabular}

Suitability of In Vitro Dissolution Test Apparatus to Simulate In Vivo Condition for Prediction of Plasma Drug Concentration through Convolution Approach

The convolution approach was used to predict the in vivo concentration of carbamazepine and ciprofloxacin in plasma from the in vitro dissolution data from both methods. This method was based on back calculation from the Wagner-Nelson method (16). Wagner and Nelson developed an equation for calculating the fraction of dose absorbed from plasma drug concentration-time profiles (in vitro data) for an open-compartment model (17). This method does not require a model assumption concerning the absorption process.

The following equation was used to compute plasma drug concentration using the in vitro dissolution data set as an input:

$$
C_{p(t+1)}=\left[\left(2 \times \Delta F_{\mathrm{a}} \times f \times D / V_{d}\right)+C_{p} \times\left(2-k_{e l} \Delta t\right)\right] /\left(2+k_{e l} \Delta t\right)
$$

where $C_{p(t+1)}$ is drug concentration following oral administration, $\Delta F_{\mathrm{a}}$ is the fraction of drug absorbed at time $t\left(\Delta F_{\mathrm{a}(t+1)}-F_{\mathrm{a}(t)}\right), D$ is the dose, $V_{\mathrm{d}}$ is the volume of distribution, $f$ is the bioavailability factor, $k_{\mathrm{el}}$ is the elimination constant, and $\Delta t=\mathrm{t}_{(t+1)}-t_{(t)}$.

The pharmacokinetics parameters of carbamazepine and ciprofloxacin (18) are presented in Table 4. The fraction of dose reaching the systemic circulation $(f)$ was considered in the calculations. The pharmacokinetic parameters such as peak plasma drug concentration $\left(C_{\max }\right)$ and time to peak plasma drug concentration in serum $\left(t_{\max }\right)$ were obtained from the product of time and calculated plasma concentration, while the area under curve $(A U C)$ was computed using the trapezoid rule.

Table 4. Pharmacokinetic Parameters of Carbamazepine and Ciprofloxacin Used in Prediction of Plasma Data Using WagnerNelson Calculations

\begin{tabular}{|c|c|c|c|c|}
\hline Drug & Dose $(\mathbf{m g})$ & $\begin{array}{c}\boldsymbol{V}_{\mathbf{d}} \\
(\mathbf{L} / \mathbf{7 0} \mathbf{~ k g})\end{array}$ & $\boldsymbol{K}_{\mathrm{el}}\left(\mathbf{h}^{-1}\right)$ & $\boldsymbol{f}$ \\
\hline Carbamazepine & 100 & 98 & 0.168 & 0.72 \\
\hline Ciprofloxacin & 500 & 140 & 0.173 & 0.69 \\
\hline
\end{tabular}

\section{RESULTS AND CONCLUSION}

The formulated microspheres and Cifran OD tablets showed similar dissolution profiles in both apparatus. The $f_{2}$ values were 57 and 56 , respectively. FDA and the European Medicines Evaluation Agency (EMEA) consider two dissolution profiles to be similar if $f_{2}$ is between 50 and 100 (20). This closeness is observed in the values presented in Table 5, which were calculated from the dissolution profiles obtained using the designed apparatus and the USP method. An average percent prediction error (\%PE) of $10 \%$ or less for $C_{\max }$ and $A U C$ establishes the predictability of the IVIVC (17). In addition, the \%PE for each method should not exceed $15 \%$.

$$
\% P E=100 \times \frac{(\text { observed }- \text { predicted })}{\text { observed }}
$$


These results indicate that the method can be used to predict the plasma data profile from in vitro release data. Generally, low prediction error values are expected (21). However, for selected floating formulations, in vivo studies would be conducted in the future to compare the predicted plasma concentrations with the observed in vivo behaviors of the formulation. A linear relationship between the in vivo percent absorbed reported in the literature (22) and the in vitro percent dissolved was found. The proposed design may offer advantages over the USP Apparatus 2 method and may be used as an alternative to Apparatus 2.

Table 5. Predicted Pharmacokinetic Parameters
\begin{tabular}{|c|c|c|c|c|c|c|}
\hline & \multicolumn{3}{|c|}{$\begin{array}{c}\text { Carbamazepine-loaded } \\
\text { floating microspheres }\end{array}$} & \multicolumn{3}{|c|}{$\begin{array}{c}\text { Ciprofloxacin floating } \\
\text { tablet } \\
\text { (CIFRAN OD) }\end{array}$} \\
\cline { 2 - 7 } & Reported $^{a}$ & USP & Proposed & Reported & USP & Proposed \\
\hline $\begin{array}{c}C_{\max } \\
(\mu \mathrm{g} / \mathrm{mL})\end{array}$ & 6.0 & 7.1 & 6.5 & 1.4 & 1.7 & 1.3 \\
\hline$\% P E$ for $C_{\max }$ & - & 18.7 & 9.0 & - & 20.7 & 9.3 \\
\hline $\begin{array}{c}A U C \\
(\mu \mathrm{g} \cdot \mathrm{h} / \mathrm{mL})\end{array}$ & 60.8 & 59.3 & 56.6 & 11.6 & 9.8 & 11.7 \\
\hline$\% P E$ for $A U C$ & - & 2.4 & 6.9 & - & 15.1 & 0.9 \\
\hline$T_{\max }(\mathrm{h})$ & 6 & 5 & 6 & 2 & 2 & 2 \\
\hline
\end{tabular}

${ }^{a}$ Data from ref 18.

\section{CONCLUSION}

The present study proposed a new apparatus to overcome the problems associated with compendial as well as noncompendial apparatus. The overall results show that the proposed design provides more biorelevance. Direct contact of floating formulations was avoided with an agitating shaft because agitation was provided from the bottom of the apparatus. Hence, the risk of the dosage form sticking to the paddles, apparatus walls, and sampling devices (pipette) was avoided. The proposed method has simplified the sampling procedure by use of a special assembly attached at the bottom of the glass apparatus. The proposed method may provide good in vivo-in vitro correlation because in vivo conditions are simulated.

The proposed dissolution apparatus can be used for the in vivo dissolution assessment of a floating dosage form as it more closely simulates most of the in vivo gastric conditions. In the future, the proposed design may stand alone in the study of dissolution profiles for any kind of floating dosage form. The proposed apparatus could be easily automated and used to study floating formulations during dosage form development. This device can thus be proposed as an alternative method to the compendial apparatus where ease of handling is a requirement.

\section{CONFLICT OF INTEREST}

No conflict of interest has been declared by the authors.

\section{ACKNOWLEDGMENTS}

The authors would like to thank N. R. Vekaria Institute of Pharmacy, Junagadh, and Anand Pharmacy College, Gujarat, India, for providing facilities for carrying out this research.

\section{REFERENCES}

1. Rolim, C. M.; Brum, L.; Fronza, M.; Malesuik, M. D.; Bajerski, L.; Dalmora, S. L. Development and Validation of an RP-HPLC Method for the Dissolution Studies of Bisoprolol in Pharmaceutical Dosage Forms. J. Liq. Chromatogr. Relat. Technol. 2005, 28 (3), 477-486. DOI:10.1081/JLC-200044531.

2. Qureshi, S. A. Comparative Impact of Stirring and Shearing in Drug Dissolution Testing with USP Paddle and Crescent-Shaped Spindles. Dissolution Technol. 2006, 13 (1), 25-30. DOI: 10.14227/DT130106P25.

3. Gohel, M. C.; Mehta, P. R.; Dave, R. K.; Bariya, N. H. A More Relevant Dissolution Method for Evaluation of Floating Drug Delivery System. Dissolution Technol. 2004, 11 (4), 22-25. DOI: 10.14227/DT110404P22.

4. Klein, S.; Shah, V. P. A Standardized Mini Paddle Apparatus as an Alternative to the Standard Paddle. AAPS PharmSciTech 2008, 9 (4), 1179-1184. DOI: 10.1208/s12249-008-9161-6.

5. Mukhopadhyay, D.; Tucker, I. G. Design and evaluation of an early stage drug release apparatus. Int. J. Pharm. 2003, 265 (1-2), 47-54. DOI: 10.1016/S03785173(03)00374-0.

6. Karande, A. D.; Yeole, P. G. Comparative Assessment of Different Dissolution Apparatus for Floating Drug Delivery Systems. Dissolution Technol. 2006, 13 (1), 20-23. DOI: 10.14227/DT130106P20.

7. Klein, S. The Mini Paddle Apparatus-a Useful Tool in the Early Developmental Stage? Experiences with Immediate-Release Dosage Forms. Dissolution Technol. 2006, 13 (4), 6-11. DOI: 10.14227/ DT130406P6.

8. Singh, S.; Sharma, S.; Hafeez, A. Dissolution: Life line of Pharmaceutics. Int. J. Pharma Prof. Res. 2011, 2 (1), 224-241.

9. Baldaniya, L. H.; Saisivam, S.; Gohel, M. C. Formulation, optimization, characterization and in vitro evaluation of sustained release floating microspheres of 
carbamazepine. Int. J. Pharma Bio Sci. 2012, 3 (2), 73-88.

10. Soppimath, K. S.; Kulkarni, A. R.; Rudzinski, W. E.; Aminabhavi, T. M. Microspheres as floating drugdelivery systems to increase gastric retention of drugs. Drug Metab. Rev. 2001, 33 (2), 149-160. DOI: 10.1081/DMR-100104401.

11. Arza, R. A.; Gonugunta, C. S.; Veerareddy, P. R. Formulation and Evaluation of Swellable and Floating Gastroretentive Ciprofloxacin Hydrochloride Tablets. AAPS PharmSciTech 2009, 10 (1), 220-226. DOI: 10.1208/s12249-009-9200-y.

12. Costa, P.; Lobo, J. M. S. Modeling and comparison of dissolution profiles. Eur. J. Pharm. Sci. 2001, 13 (2), 123-133. DOI: 10.1016/S0928-0987(01)00095-1.

13. Soni, T.; Nagda, C.; Gandhi, T.; Chotai, N. P. Development of Discriminating Method for Dissolution of Aceclofenac Marketed Formulations. Dissolution Technol. 2008, 15 (2), 31-35. DOI: 10.14227/DT150208P31.

14. Moore, J. W.; Flanner, H. H. Mathematical Comparison of Curves with an Emphasis on In vitro Dissolution Profiles. Pharm. Technol. 1996, 20 (6), 64-74.

15. Gray, V.; Kelly, G.; Xia, M.; Butler, C.; Thomas, S.; Mayock, S. The Science of USP 1 and 2 Dissolution: Present Challenges and Future Relevance. Pharm. Res. 2009, 26 (6), 1289-1302. DOI: 10.1007/s11095008-9822-x.

16. Gohel, M.; Delvadia, R.; Parikh, D.; Zinzuwadia, M.; Soni, C.; Sarvaiya, K.; Mehta, N.; Joshi, B.; Dabhi, A. Simplified Mathematical Approach for Back Calculation in Wagner-Nelson Method: Applications in In Vitro and In Vivo Correlation (IVIVC) and formulation Development Work. Pharm. Rev. 2005, 3 (2), 1-8.

17. Bendas, E. R. Two Different Approaches for the Prediction of In Vivo Plasma Concentration-Time Profile from In Vitro Release Data of Once Daily Formulations of Diltiazem Hydrochloride. Arch. Pharmacal Res. 2009, 32 (9), 1317-1329. DOI: 10.1007/s12272-009-1918-2.

18. Goodman \& Gilman's The Pharmacological Basis of Therapeutics, 12th ed.; Brunton, L. L., Chabner, B. A., Knollmann, B. C., Eds.; McGraw-Hill: New York, 2012; pp 1915.

19. Shah, V. P.; Tsong, Y.; Sathe, P.; Liu, J. P. In vitro Dissolution Profile Comparison-Statistics and
Analysis of the Similarity Factor, f2. Pharm. Res. 1998, 15 (6), 889-896. DOI: 10.1023/A:1011976615750.

20. Extended Release Oral Dosage Forms: Development, Evaluation, and Application of In Vitro/In Vivo Correlations; Guidance for Industry; U.S. Department of Health and Human Services, Food and Drug Administration, Center for Drug Evaluation and Research (CDER), U.S. Government Printing Office: Washington, DC, 1997.

21. Korhonen, O.; Kanerva, H.; Vidgren, M.; Urtti, A.; Ketolainen, J. Evaluation of novel starch acetatediltiazem controlled release tablets in healthy human volunteers. J. Controlled Release 2004, 95, 515-520. DOI: 10.1016/j.jconrel.2003.12.026.

22. Barzegar-Jalali, M.; Nayebi, A. M.; Valizadeh, H.; Hanaee, J.; Barzegar-Jalali, A., Adibkia, K. Evaluation of in vitro-in vivo correlation and anticonvulsive effect of carbamazepine after cogrinding with microcrystalline cellulose. J. Pharm. Pharm. Sci. 2006, 9 (3), 307-316. 